\title{
Circuit-based method for extracting the resistive leakage current of metal oxide surge arrester
}

\author{
Amir Hesam Khavari ${ }^{1}$, Abdullah Munir ${ }^{2}$, Zulkurnain Abdul-Malek ${ }^{3}$ \\ ${ }^{1,3}$ Institute of High Voltage and High Current, School of Electrical Engineering, Faculty of Engineering, \\ Universiti Teknologi Malaysia, Malaysia \\ ${ }^{2}$ Department of Electrical Engineering, NED University of Engineering and Technology, Pakistan
}

\begin{tabular}{|c|c|}
\hline Article Info & ABSTRACT \\
\hline Article history: & \multirow{10}{*}{$\begin{array}{l}\text { Resistive leakage current based condition assessment of metal oxide surge } \\
\text { arrester (MOSA) is one of the most extensively employed technique to } \\
\text { monitor its degradation. An extraction method is customarily required to } \\
\text { extract the resistive component from the total leakage current. The existing } \\
\text { methods to extract the resistive current are complex and less accurate. } \\
\text { Therefore, this paper describes a simple and accurate circuit-based method to } \\
\text { extract the resistive current using equivalent model and measured leakage } \\
\text { current of the arrester. The accuracy of the proposed method is validated } \\
\text { through experimental results on ABB's } 120 \mathrm{kV} \text { surge arrester, EMTP } \\
\text { and QuickField software simulations. The performance of the method is also } \\
\text { analyzed and verified experimentally on } 72,180 \text { and } 240 \mathrm{kV} \text { rated ABB's } \\
\text { surge arresters. The obtained results of resistive leakage current have shown } \\
\text { the maximum error of } 0.001 \% \text {. Simple and easier computational steps with } \\
\text { higher accuracy are the key benefits of the proposed technique. }\end{array}$} \\
\hline Received Feb 17, 2020 & \\
\hline Revised Apr 24, 2020 & \\
\hline Accepted May 9, 2020 & \\
\hline Keywords: & \\
\hline Condition monitoring & \\
\hline Degradation & \\
\hline Metal oxide surge arrester & \\
\hline Resistive leakage current & \\
\hline Total leakage current & \\
\hline
\end{tabular}

This is an open access article under the $\underline{C C B Y-S A}$ license.

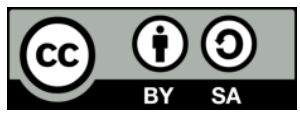

\section{Corresponding Author:}

Zulkurnain Abdul-Malek, Institute of High Voltage and High Current, School of Electrical Engineering, Faculty of Engineering, Universiti Teknologi Malaysia, 81310 UTM Johor Bahru, Malaysia

Email: zulkurnain@utm.my

\section{INTRODUCTION}

Surge arresters are employed to protect the transmission system from the over voltage caused by lightning and switching operations in the power system [1]. The general types of arresters are silicon carbide-based arresters with spark gaps and gapless metal oxide arresters. Gapped arresters are not able to limit the switching overvoltage effectively [2]. Therefore, the gapless arresters are developed; the most popular MOSA is the zinc oxide arrester [3]. Zinc oxide element offers high nonlinear voltage current characteristics and faster conduction response for high voltage surges [4,5]. As the resistance of zinc oxide element cannot be made infinity, therefore it draws a continuous current at the normal operating voltage, known as leakage current $[6,7]$. The arrester's total leakage current consists of the resistive and capacitive components [8]. The resistive current varies with the changes in zinc oxide's characteristics, operating voltage, ambient temperature, and environmental factors [9-12]. Therefore, it can be used as the most reliable indicator of ageing and degradation of MOSA [13].

Many techniques have been proposed for the extraction of resistive leakage current which include; capacitive current compensation method [14, 15], field probe method [16, 17] and current orthogonality method [4, 18-21]. In the current compensation method, the capacitive current is compensated by adjusting the amplitude and phase angle of the reference signal but the presence of harmonics in the capacitive current may interfere with the measurement of the nonlinear resistive current. In the field probe method, the third 
harmonic capacitive current by voltage harmonics is compensated with the help of a compensating current signal but the effect of voltage distortion on third harmonic resistive current is not considered. Similarly, the modified shifted current method [18-20], time delay addition method [21], and current orthogonality method [22] are proposed, which are based on the displacement of the resistive and capacitive components of the leakage current. Modified shifted current and time delay addition methods are based on waveform manipulation of the obtained leakage current. A capacitive current waveform with a shifted phase of $\pi$ radians is injected to the total leakage current to compensate the capacitive current component. The magnitude of the capacitive current is determined at the time instant, which has a time delay of $\pi / 2$ radians with respect to the peak time of resistive current waveform [23]. However, the results of acquired resistive current are more accurate as compared to the conventional compensation technique. But, the accuracy of results is affected in the case of non-sinusoidal applied voltage [24]. Lot of complex and complicated steps are required to extract the resistive current in these methods and the results are not enough accurate [25]. Therefore, the implementation of an extraction method with simpler computational steps and better accuracy provides a potential research area. The aim of this paper is to propose a simpler and accurate computational circuit-based method for the extraction of the resistive leakage current of MOSA. The proposed method is based on the measurement of total leakage current and mathematical equations derived from the equivalent model of MOSA. The accuracy of method is validated experimentally on ABB's $120 \mathrm{kV}$ surge arrester and through particulars software such as EMTP and QuickField. Its performance is also tested experimentally on 72,180 and $240 \mathrm{kV}$ surge arresters. The obtained results have revealed that the proposed method has higher accuracy with minimum error of $0.001 \%$. Furthermore, the implementation procedure is quite easy and simpler as compared to other existing methods.

\section{RESEARCH METHOD}

\subsection{Equivalent circuit of MOSA}

An equivalent circuit model of MOSA as shown in Figure 1, is required to determine the circuit element values and resistive leakage current [26]. In Figure 1 ' $\mathrm{V}_{\mathrm{s}}$ ', ' $\mathrm{I}_{\mathrm{t}}$ ' and ' $\mathrm{I}_{\mathrm{r}}$ ' represent the supply voltage, total and resistive leakage current respectively. Equestion (1) presents the orthogonal relation between the resistive and capacitive components of the total leakage current.

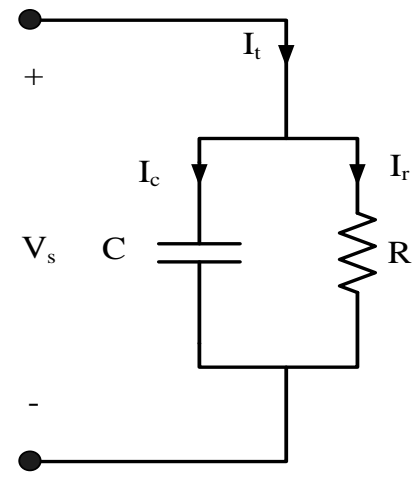

Figure 1. An Equivalent circuit model of MOSA

$$
\mathrm{I}_{\mathrm{t}}=\mathrm{I}_{\mathrm{c}}+\mathrm{I}_{\mathrm{r}}
$$

The capacitance ' $C$ ' and resistance ' $R$ ' in the circuit model depend on the electrical properties and dimensions of the MOSA column. 'C' can be determined using (2).

$$
C=\frac{\varepsilon_{0} \varepsilon_{r} A}{d}
$$

Where;

$\varepsilon_{\mathrm{o}}=$ Vacuum permittivity

$\varepsilon_{\mathrm{r}}=$ Relative permittivity of the arrester disc 
$\mathrm{A}=$ Area of the MOSA disc

$\mathrm{d}=$ Height of the column of MOSA disc

Furthermore, the resistivity ' $\rho$ ' and resistance ' $R$ ' of the MOSA disc can be represented as a function of the applied voltage ' $\mathrm{V}_{\mathrm{s}}$ ' in (3) and (4).

$$
\begin{aligned}
& \rho=f\left(V_{s}\right) \\
& R(V s)=\frac{\rho\left(V_{S}\right) d}{A}
\end{aligned}
$$

\section{2. $V_{s}-I_{t}$ characteristic curve of the surge arrester}

The voltage-current characteristic curve, as shown in Figure 2, shows the non-linear variation of applied voltage and the total leakage current. Three regions are defined in $V_{s}-I_{t}$ curve based on applied voltage. Four points are destined in the region $\mathrm{I}$, known as the steady state region. At the first point $\left(\mathrm{V}_{\mathrm{C}}\right)$, the total leakage current of the MOSA is mainly capacitive. While the other points are the phase to earth voltage $\left(V_{P-N}\right)$, continuous operating voltage $\left(\mathrm{V}_{\mathrm{COV}}\right)$ and rated voltage $\left(\mathrm{V}_{\text {rated }}\right)$. A small increase in the voltage increases the leakage current significantly in the region II, called the flat region. The temporary over voltage $\left(\mathrm{V}_{\mathrm{TOV}}\right)$ also occurs in region II. Whereas, in the region III known as an arrester operation region, MOSA operates to discharge the lightning current. The discharge voltage, which appears in this region is called ' $\mathrm{V}_{10}$ '. The considered values of the voltages such as $\mathrm{V}_{\mathrm{c}}, \mathrm{V}_{\mathrm{P}-\mathrm{N}}, \mathrm{V}_{\mathrm{COV}}$ and $\mathrm{V}_{\text {rated }}$ are presented in the Table 1.

Table 1. Considered value of $V_{c}, V_{P-N}, V_{C O V}$ and $V_{\text {rated }}$ for $120 \mathrm{kV}$ surge arrester

\begin{tabular}{cc}
\hline Parameter & Value \\
\hline$V_{c}$ & $10 k V_{\text {rms }}$ \\
$V_{P-N}$ & $93 k V_{\text {rms }}$ \\
$V_{\text {COV }}$ & $98 k V_{\text {rms }}$ \\
$V_{\text {rated }}$ & $120 \mathrm{kV}_{\text {rms }}$ \\
\hline
\end{tabular}

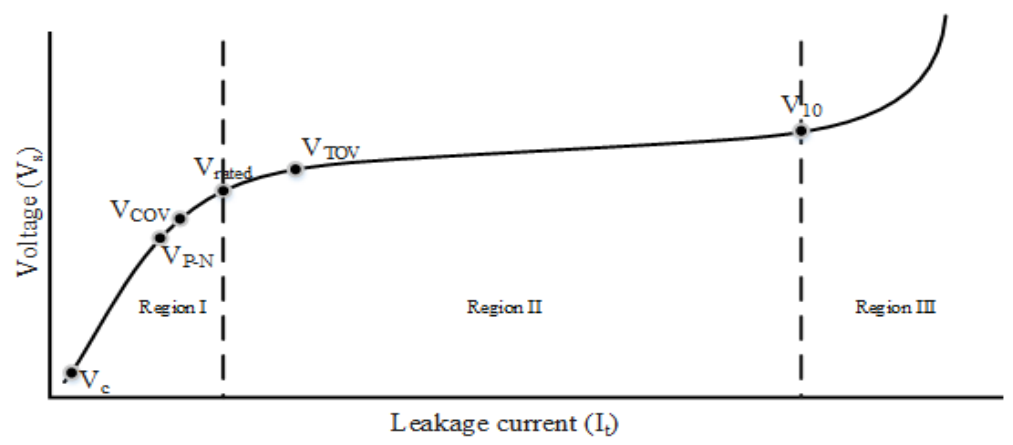

Figure 2. $V_{s}-I_{t}$ characteristic trend of a typical MOSA

\subsection{Extraction of the resistive leakage current using mathematical procedure}

The relationship between the applied voltage and total leakage current based on the equivalent circuit of Figure 1 is given in (5), where ' $Z$ ' is the impedance of the equivalent circuit of MOSA. At the voltage levels, $\mathrm{V}_{\mathrm{c}}<\mathrm{V}_{\mathrm{s}}$, the contribution of the resistive component in the total leakage current is negligible. Therefore, the impedance of the circuit model is given in (6).

$$
\begin{aligned}
& \mathrm{V}_{\mathrm{s}}=\mathrm{I}_{\mathrm{t}} \mathrm{Z} \\
& Z=X_{c}=\frac{1}{\omega C}
\end{aligned}
$$

Where;

$\mathrm{X}_{\mathrm{c}}=$ Capacitive reactance of the circuit $\omega=$ Angular Frequency 
The capacitance of the MOSA disc (shown in 7) can be determined by substituting (5) and (6) into (1) and by considering ' $\mathrm{I}_{\mathrm{t}}$ ' as ' $\mathrm{I}_{\mathrm{c}}$ ' and ' $\mathrm{V}_{\mathrm{s}}$ ' as ' $\mathrm{V}_{\mathrm{c}}$ '. Similarly, the capacitive leakage current in the steady state condition (as shown in (8)) is obtained by equating (2) and (7). The resistive leakage current can easily be calculated after determining the capacitive current.

$$
\begin{aligned}
C & =\frac{I_{C}}{\omega V_{c}} \\
I_{C} & =\frac{\epsilon_{0} \epsilon_{r} A}{d}\left(V_{c} \times 2 \pi \times 50\right)
\end{aligned}
$$

\subsection{Experimental procedure}

The experimental setup to measure the total leakage current of ABB's $120 \mathrm{kV}$ surge arrester is shown in Figure 3. The thickness of each disc of the arrester is $2.5 \mathrm{~cm}$ while the height of the column of ' $\mathrm{d}^{\prime}$ and radius ' $r$ ' of the disc are $100 \mathrm{~cm}$ and $3.5 \mathrm{~cm}$ respectively. A high voltage transformer (HVT) is connected in series with a pure resistor of $970 \Omega$ to apply voltage to the tested arrester. The voltage across the shunt resistor is used to determine the total leakage current $I_{t}$. The magnitude and waveform of the peak voltage across the resistor is measured and recorded by digital oscilloscope (Osc).

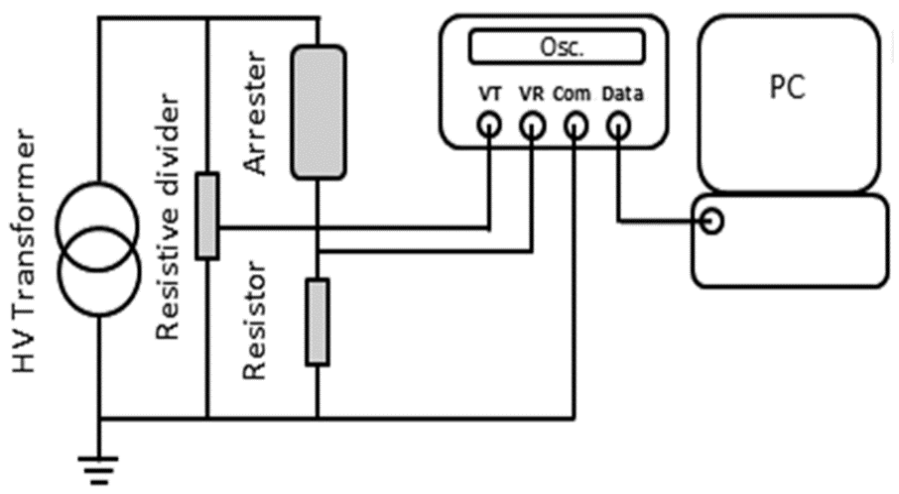

Figure 3. Schematic diagram of experimental setup

\subsection{Validation of proposed method by EMTP software}

In order to validate the results of the proposed technique, initially the circuit model of MOSA as shown in Figure 1 is designed in EMTP software. The capacitance of the equivalent model is calculated using (2). The non-linear resistance of the arrester is determined using the curve fitting technique based on the plotted $V_{s}-I_{r}$ curve of Figure 4. The resistive leakage current as a function of applied voltage is then computed using (9). The obtained resistive leakage current using EMTP software is compared with the results of proposed method and is presented in the result's section.

$$
I_{r}=\frac{V_{S}}{R}
$$

\subsection{Validation of proposed method using quickfield software}

The electrical properties such as relative permittivity $\left(\epsilon_{r}\right)$, and resistivity $(\rho)$ are required for finite element modelling in the software. The obtained resistive leakage current using QuickField software is compared with the results of proposed method and is presented in the result's section.

\section{RESULTS AND DISCUSSION}

The proposed method is applied to compute the capacitive and resistive components based on the measurement of total leakage current in the experimental test described in section 2.3. The obtained results for a $120 \mathrm{kV}$ MOSA are presented in Table 2. The data in the first three columns of $V_{r m s}$, $V_{\text {peak }}$, and $I_{t}$ is obtained from the experimental test. While, the last two columns of $I_{c}$ and $I_{r}$ are computed using the proposed technique. By analysing the values of $I_{t}, I_{c}$ and $I_{r}$, it is found that the leakage current is dominantly capacitive for the voltage level up to the continuous operating voltage of $98 \mathrm{kV}_{\text {rms. }}$. 
However, the resistive current significantly increases for voltages above $120 \mathrm{kV}_{\text {rms. }}$ The variation of $I_{t}, I_{r}$ and $I_{c}$ with the applied voltage can be seen in Figure 4 based on the values from Table 2 . The $V_{s}-I_{r}$ characteristic is linear for the applied voltages in the range of 14.14 to $131.52 \mathrm{kV}$ peak as shown in Figure 4. It can be said that $V_{P-N}$ is the knee point of the $V_{S}-I_{r}$ curve of the arrester. After $V_{P-N}$, the resistive current shows a non-linear characteristic. Whereas, the variation of the capacitive current is linear for all ranges of the applied voltage.

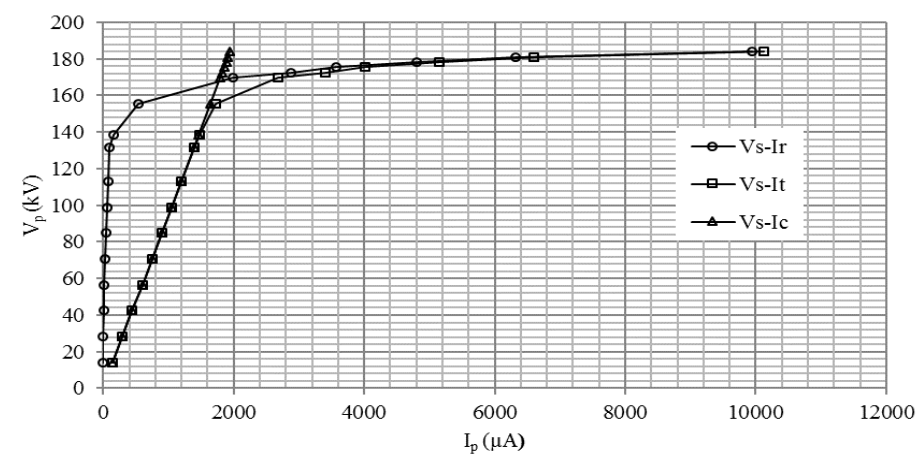

Figure 4. The variation of resistive current $\left(\mathrm{I}_{\mathrm{r}}\right)$, capacitive current $\left(\mathrm{I}_{\mathrm{c}}\right)$ and total leakage current $\left(\mathrm{I}_{\mathrm{t}}\right)$ of $120 \mathrm{kV}$ MOSA with the applied voltage using the proposed computational method

Table 2. Computed capacitive and resistive leakage current of $120 \mathrm{kV}$ surge arrester using the proposed mathematical method

\begin{tabular}{ccccc}
\hline $\begin{array}{c}V_{r m s} \\
(\mathrm{kV})\end{array}$ & $\begin{array}{c}V_{\text {Peak }} \\
(\mathrm{kV})\end{array}$ & $\begin{array}{c}I_{t} \\
(\mu \mathrm{A})\end{array}$ & $\begin{array}{c}I_{c} \\
(\mu \mathrm{A})\end{array}$ & $\begin{array}{c}I_{r} \\
(\mu \mathrm{A})\end{array}$ \\
\hline 10 & 14.14 & 149.48 & 149.48 & 0.80 \\
20 & 28.28 & 298.98 & 298.96 & 1.61 \\
30 & 42.42 & 448.56 & 448.45 & 2.41 \\
40 & 56.56 & 598.14 & 597.93 & 3.22 \\
50 & 70.71 & 747.94 & 747.41 & 4.02 \\
60 & 84.85 & 897.94 & 896.89 & 4.82 \\
70 & 98.99 & 1047.94 & 1046.38 & 5.63 \\
80 & 113.13 & 1197.94 & 1195.86 & 70.55 \\
93 & 131.52 & 1393.81 & 1390.19 & 100.51 \\
98 & 138.59 & 1474.23 & 1464.93 & 165.33 \\
110 & 155.56 & 1731.96 & 1644.31 & 544.00 \\
120 & 169.70 & 2680.41 & 1793.79 & 1991.72 \\
130 & 183.84 & 10124.74 & 1943.27 & 9936.50 \\
\hline
\end{tabular}

\subsection{Validation of proposed method by EMTP software}

Based on the data presented in Table 3 to design the equivalent circuit model of MOSA, the capacitance is found to be $33 \mathrm{pF}$. The resistive leakage current as a function of the applied voltage at the steady state condition by using the curve fitting technique is given in (10), which can be substituted in (9) to determine the resistance. The voltage dependent function of resistance $R\left(V_{s}\right)$ is shown in (11). The obtained values of resistance at $\mathrm{V}_{c}, \mathrm{~V}_{\mathrm{P}-\mathrm{N}}, \mathrm{V}_{\mathrm{COV}}$ and $\mathrm{V}_{\text {rated }}$ are presented in Table 4 . The peak values of the total leakage current and its resistive and capacitive components are presented in Table 5.

$$
\begin{aligned}
& I_{r}\left(V_{S}\right)=0.0038 \times e^{0.0774 v_{S}} \\
& R\left(V_{s}\right)=\frac{V_{S}}{0.0038 \times e^{0.0774 v_{S}}}
\end{aligned}
$$

Table 3. Computed data for $120 \mathrm{kV}$ surge arrester

\begin{tabular}{ccc}
\hline Parameter & Formula & Value \\
\hline $\mathrm{C}$ & $\frac{\epsilon x A}{d}$ & $33 \mathrm{pF}$ \\
$\epsilon$ & $\epsilon_{0} \epsilon_{r}$ & $8.68(\mathrm{nF} / \mathrm{m})$ \\
$\mathrm{A}$ & $\pi r^{2}$ & $0.003848\left(\mathrm{~m}^{2}\right)$ \\
$\mathrm{d}$ & - & $1(\mathrm{~m})$ \\
\hline
\end{tabular}


Table 4. Resistance of surge arrester at different voltages

\begin{tabular}{ccc}
\hline $\begin{array}{c}\text { Applied voltage }\left(V_{s}\right) \\
\text { (rms value) }\end{array}$ & $\begin{array}{c}\text { Applied voltage }\left(V_{s}\right) \\
\text { Peak value }\end{array}$ & $\begin{array}{c}\text { Resistance of the } \\
\text { arrester } \\
R\left(V_{s}\right)\end{array}$ \\
\hline $10 \mathrm{kV}_{\text {rms }}$ & $14.14 \mathrm{kV}$ & $1.24 T \Omega$ \\
$93 \mathrm{kV}_{\text {rms }}$ & $131.52 \mathrm{kV}$ & $1.31 \mathrm{G} \Omega$ \\
$98 \mathrm{kV}_{\text {rms }}$ & $138.59 \mathrm{kV}$ & $800 \mathrm{M} \Omega$ \\
$120 \mathrm{kV} V_{\text {rms }}$ & $169.7 \mathrm{kV}$ & $88 \mathrm{M} \Omega$ \\
\hline
\end{tabular}

$\underline{\text { Table 5. Simulation results of } 120 \mathrm{kV} \text { surge arrester modeled in EMTP }}$

\begin{tabular}{ccccc}
\hline $\begin{array}{c}V_{r m s} \\
(\mathrm{kV})\end{array}$ & $\begin{array}{c}V_{\text {Peak }} \\
(\mathrm{kV})\end{array}$ & $\begin{array}{c}I_{t} \\
(\mu \mathrm{A})\end{array}$ & $\begin{array}{c}I_{c} \\
(\mu \mathrm{A})\end{array}$ & $\begin{array}{c}I_{r} \\
(\mu \mathrm{A})\end{array}$ \\
\hline 10 & 14.14 & 147.95 & 146.6 & 0.80 \\
93 & 131.52 & 1379.53 & 1363.49 & 100.20 \\
98 & 138.59 & 1460.03 & 1436.83 & 173.18 \\
120 & 169.70 & 2617.86 & 1759.36 & 1924.55 \\
\hline
\end{tabular}

\subsection{Validation of proposed method by quickfield software}

The relative permittivity can be derived by substituting the dimensions of the arrester in (2) and non-linear resistivity formula (derived from (4)) is given in (12). The electrical conductivity $(\sigma)$ can be determined by taking the reciprocal of resistivity as shown in (13). The obtained values of resistivity and conductivity at different values of applied voltages is presented in Table 6. The simulation results of the leakage current values are shown in Table 7.

$$
\begin{aligned}
& (\rho(V))=\frac{\pi r^{2} \times V_{S}}{0.0038 d \times e^{0.0774 V_{S}}}=\frac{\pi r^{2} \times R\left(V_{S}\right)}{d} \\
& =\frac{1}{\rho}
\end{aligned}
$$

Table 6. Electrical resistivity values of $120 \mathrm{kV}$ surge arrester at different values of applied voltage

\begin{tabular}{ccc}
\hline Applied peak voltage $\left(V_{s}\right)$ & $\begin{array}{c}\text { Electrical resistivity of the } \\
\text { arrester } \rho(G \Omega . m)\end{array}$ & $\begin{array}{c}\text { Electrical conductivity of } \\
\text { the arrester } \sigma(\mathrm{s} / \mathrm{m})\end{array}$ \\
\hline $14.14 \mathrm{kV}$ & 4.79 & $2.086 \times 10^{-10}$ \\
$131.52 \mathrm{kV}$ & 0.005 & $1.9793 \times 10^{-7}$ \\
$138.59 \mathrm{kV}$ & 0.003 & $3.2469 \times 10^{-7}$ \\
$169.7 \mathrm{kV}$ & 0.00033 & $2.9468 \times 10^{-6}$ \\
\hline
\end{tabular}

Table 7. Simulation results of $120 \mathrm{kV} \mathrm{ZnO}$ arrester modeled in quickfield

\begin{tabular}{ccccc}
\hline $\begin{array}{c}V_{\text {rms }} \\
(\mathrm{kV})\end{array}$ & $\begin{array}{c}V_{\text {Peak }} \\
(\mathrm{kV})\end{array}$ & $\begin{array}{c}I_{t} \\
(\mu \mathrm{A})\end{array}$ & $\begin{array}{c}I_{c} \\
(\mu \mathrm{A})\end{array}$ & $\begin{array}{c}I_{r} \\
(\mu \mathrm{A})\end{array}$ \\
\hline 10 & 14.14 & 147.84 & 147.84 & 0.1 \\
93 & 131.52 & 1378.42 & 1374.72 & 100.99 \\
98 & 138.59 & 1458.23 & 1447.68 & 175.10 \\
120 & 169.70 & 2628.28 & 1774.08 & 1939.20 \\
\hline
\end{tabular}

\subsection{Comparison between the computed and simulated results}

The implementation of the proposed technique yields computed results whereas the simulated results can be obtained by using software. Table 8 shows less than $1 \%$ difference between the obtained leakage current by computation and simulation using EMTP software. Moreover, the differences between the simulated and computed resistive and capacitive components of the leakage current are less than 5\% and $2 \%$ respectively. This difference arises due to curve fitting technique to evaluate the resistive leakage current at continuous operating voltage. Similarly, Table 9 shows less than $1 \%$ difference between the computed and simulated resistive and capacitive leakage currents modelled in QuickField software. 
Table 8. Comparison between simulated and calculated results of $120 \mathrm{kV}$ surge arrester modeled in EMTP software

\begin{tabular}{ccccccc}
\hline \multirow{2}{*}{$\begin{array}{c}V_{\mathrm{rms}} \\
(\mathrm{kV})\end{array}$} & \multicolumn{2}{c}{$\begin{array}{c}\mathrm{I}_{\mathrm{t}} \\
\mu \mathrm{A})\end{array}$} & \multicolumn{2}{c}{$\begin{array}{c}\mathrm{I}_{\mathrm{c}} \\
(\mu \mathrm{A})\end{array}$} & \multicolumn{2}{c}{$\begin{array}{c}\mathrm{I}_{\mathrm{r}} \\
(\mu \mathrm{A})\end{array}$} \\
\cline { 2 - 7 } & Simulation & Computation & Simulation & Computation & Simulation & Computation \\
\hline 10 & 147.95 & 149.48 & 146.6 & 149.48 & 0.80 & 0.80 \\
93 & 1379.53 & 1393.81 & 1363.49 & 1390.19 & 100.20 & 100.51 \\
98 & 1460.03 & 1474.23 & 1436.83 & 1464.93 & 173.18 & 165.33 \\
120 & 2617.86 & 2680.41 & 1759.36 & 1793.79 & 1924.55 & 1991.72 \\
\hline
\end{tabular}

Table 9. Comparison between simulated and calculated results of $120 \mathrm{kV}$ surge arrester modeled in QuickField software

\begin{tabular}{ccccccc}
\hline & \multicolumn{2}{c}{$\begin{array}{c}\mathrm{I}_{\mathrm{t}} \\
\mathrm{V}_{\mathrm{rms}}\end{array}$} & \multicolumn{2}{c}{$(\mu \mathrm{A})$} & \multicolumn{2}{c}{$\begin{array}{c}\mathrm{I}_{\mathrm{c}} \\
(\mu \mathrm{A})\end{array}$} \\
\cline { 2 - 7 }$(\mathrm{kV})$ & Simulation & Computation & Simulation & Computation & Simulation & \multicolumn{1}{c}{$\begin{array}{c}\mathrm{I}_{\mathrm{r}} \\
(\mu \mathrm{A})\end{array}$} \\
\hline 10 & 147.84 & 149.48 & 147.84 & 149.48 & 0.1 & 0.80 \\
93 & 1378.42 & 1393.81 & 1374.72 & 1390.19 & 100.99 & 100.51 \\
98 & 1458.23 & 1474.23 & 1447.68 & 1464.93 & 175.10 & 165.33 \\
120 & 2628.28 & 2680.41 & 1774.08 & 1793.79 & 1939.20 & 1991.72 \\
\hline
\end{tabular}

\section{CONCLUSION}

In this paper, a circuit-based method for the extraction of the resistive leakage current has been proposed. The accuracy of the proposed computational method has been validated using $120 \mathrm{kV}$ surge arrester's experimental results and software such as EMTP and QuickField. Also, the performance of the proposed method has been compared and tested for ABB's 72, 180 and $240 \mathrm{kV}$ rated surge arresters. The obtained results have shown that the implementation of this proposed technique requires less computational steps with higher accuracy as compared to existing methods. The error between the simulated and calculated resistive current values has been found to be $0.001 \%$, which is quite less than the errors obtained from the available methods. In the future, it is aimed to modify the proposed technique to extract the online resistive leakage current of MOSA.

\section{ACKNOWLEDGEMENTS}

Authors wish to thank Malaysian Ministry of Education (4F828), Universiti Teknologi Malaysia (18H10 \& 01M44) and Universitas Sriwijaya (4B345 \& 4B279) for the financial support.

\section{REFERENCES}

[1] C. Wooi, Z. Abdul-Malek, and S. Mashak, "Effect of ambient temperature on leakage current of gapless metal oxide surge arrester," Jurnal Teknologi, vol. 64, no. 4, pp. 157-161, 2013.

[2] V. Vita, A. Mitropoulou, L. Ekonomou, S. Panetsos, and I. Stathopulos, "Comparison of metal-oxide surge arresters circuit models and implementation on high-voltage transmission lines of the Hellenic network," IET generation, transmission \& distribution, vol. 4, no. 7, pp. 846-853, 2010.

[3] T. T. Hoang, M.-Y. Cho, M. N. Alam, and Q. T. Vu, "A novel differential particle swarm optimization for parameter selection of support vector machines for monitoring metal-oxide surge arrester conditions," Swarm and Evolutionary Computation, vol. 38, pp. 120-126, 2018.

[4] M. Olesz, "Determining the leakage current resistive component by the orthogonal vector method," 2018 34th International Conference on Lightning Protection (ICLP), Rzeszow, pp. 1-4, 2018.

[5] N. A. Latiff, H. A. Illias, A. H. Bakar, and S. Z. Dabbak, "Measurement and Modelling of Leakage Current Behaviour in $\mathrm{ZnO}$ Surge Arresters under Various Applied Voltage Amplitudes and Pollution Conditions," Energies, vol. 11, no. 4, p. 875, 2018.

[6] S. M. Arshad and A. S. Rodrigo, "Modified Phase Shifting of Leakage Current to Condition Monitoring of Metal Oxide Surge Arresters in Power System," 2018 Moratuwa Engineering Research Conference (MERCon), Moratuwa, pp. 300-305, 2018.

[7] W. Doorsamy and P. Bokoro, "On-line monitoring of metal-oxide surge arresters using improved equivalent model with evolutionary optimisation algorithm," 2017 IEEE 26th International Symposium on Industrial Electronics (ISIE), Edinburgh, pp. 135-139, 2017.

[8] Z. Fu, J. Wang, A. Bretas, Y. Ou and G. Zhou, "Measurement Method for Resistive Current Components of Metal Oxide Surge Arrester in Service," in IEEE Transactions on Power Delivery, vol. 33, no. 5, pp. 2246-2253, Oct. 2018. 
[9] M. Khodsuz and M. Mirzaie, "Evaluation of ultraviolet ageing, pollution and varistor degradation effects on harmonic contents of surge arrester leakage current," IET Science, Measurement \& Technology, vol. 9, no. 8, pp. 979-986, 2015.

[10] J. Wu, J. Hu, S. Chen, and J. He, "Harmonic Characteristics of Leakage Currents of ZnO Varistors Under Impulse Aging," IEEE Transactions on Power Delivery, vol. 32, no. 4, pp. 1758-1765, 2017.

[11] C. de Salles, T. A. Nogueira, E. T. W. Neto, M. L. B. Martinez, and A. A. A. de Queiroz, "Effects of operation temperature in artificially aging of zinc oxide varistors by high current short impulses," Electric Power Systems Research, vol. 134, pp. 145-151, 2016.

[12] S. Das, R. Ghosh, S. Dalai, and B. Chatterjee, "Study on the effect of moisture ingression into metal oxide surge arrester using leakage current analysis," 2017 3rd International Conference on Condition Assessment Techniques in Electrical Systems (CATCON), Rupnagar, pp. 330-334, 2017.

[13] N. Novizon, Z. Malek, N. Bashir, and N. Asilah, "Thermal Image and Leakage Current Diagnostic as a Tool for Testing and Condition Monitoring of ZnO Surge Arrester," Jurnal Teknologi, vol. 64, no. 4, 2013.

[14] S. Shirakawa, F. Endo, H. Kitajima, S. Kobayashi, K. Goto, and M. Sakai, "Maintenance of surge arrester by a portable arrester leakage current detector," IEEE Transactions on Power Delivery, vol. 3, no. 3, pp. 998-1003, July 1988.

[15] J. Chen, L. Xu, Z. Wan, X. Hu, and L. Zhang, "Research on monitor technology of MOA state based on third harmonic principle," 2016 IEEE International Conference on High Voltage Engineering and Application (ICHVE), Chengdu, pp. 1-4, 2016.

[16] J. Lundquist, L. Stenstrom, A. Schei, and B. Hansen, "New method for measurement of the resistive leakage currents of metal-oxide surge arresters in service," in IEEE Transactions on Power Delivery, vol. 5, no. 4, pp. 1811-1822, 1990.

[17] H. Zhu, "Investigation of on-site diagnostic testing techniques for metal oxide surge arresters," A thesis Faculty of Graduate Studies in Partial Fultillment of the Requirements, 2000.

[18] Z. Abdul-Malek, N. Yusoff, and M. F. M. Yousof, "Field experience on surge arrester condition monitoringModified Shifted Current Method," 45th International Universities Power Engineering Conference UPEC2010, Cardiff, Wales, pp. 1-5, 2010.

[19] Z. Abdul-Malek, Novizon, and Aulia, "A new method to extract the resistive component of the metal oxide surge arrester leakage current," 2008 IEEE 2nd International Power and Energy Conference, Johor Bahru, pp. 399-402, 2008.

[20] A.-M. Zulkurnain, Novizon, and Aulia, "Portable device to extract resistive component of the metal oxide surge arrester leakage current," in 2008 Australasian Universities Power Engineering Conference, 2008 Australasian Universities Power Engineering Conference, Sydney, NSW, pp. 1-5, 2008.

[21] B.-H. Lee and S.-M. Kang, "A new on-line leakage current monitoring system of ZnO surge arresters," Materials Science and Engineering: B, vol. 119, no. 1, pp. 13-18, 2005.

[22] Z.-n. Xu, L.-j. Zhao, A. Ding, and F.-c. Lu, "A current orthogonality method to extract resistive leakage current of MOSA," IEEE Transactions on Power Delivery, vol. 28, no. 1, pp. 93-101, Jan 2013.

[23] Y. Han, Z. Li, H. Zheng, and W. Guo, "A decomposition method for the total leakage current of MOA based on multiple linear regression," in IEEE transactions on power delivery, vol. 31, no. 4, pp. 1422-1428, 2016.

[24] Y. Han, Z. Li, and H. Zheng, "A new method to extract the resistive current of MOA based on least square," in 2015 IEEE 11th International Conference on the Properties and Applications of Dielectric Materials (ICPADM), Sydney, NSW, pp. 312-315, 2015.

[25] W. Doorsamy and P. Bokoro, "Condition Monitoring of Metal-oxide Surge Arresters using Leakage Current Signal Analysis," 2018 IEEE International Conference on High Voltage Engineering and Application (ICHVE), ATHENS, Greece, pp. 1-4, 2018.

[26] H. Zhu and M. Raghuveer, "Influence of representation model and voltage harmonics on metal oxide surge arrester diagnostics," in IEEE Transactions on Power Delivery, vol. 16, no. 4, pp. 599-603, Oct. 2001.

\section{BIOGRAPHIES OF AUTHORS}

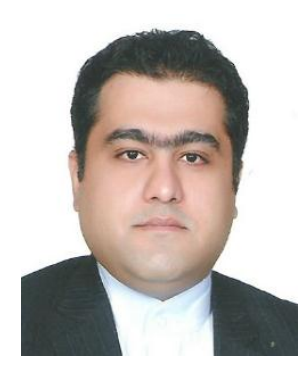

Amir Hesam Khavari received the B.Sc. degree in electrical engineering from Islamic Azad University, Iran, in 2008, the M.Sc. and the Ph.D. degrees in electrical power engineering from Universiti Teknologi Malaysia (UTM), Johor Bahru, Malaysia in 2012 and 2018, respectively. $\mathrm{He}$ is currently an assistant professor at the faculty of electrical engineering, Islamic Azad University, Iran, and also, is an employee at Tehran Regional Electricity Company (TREC) as an electrical transmission and sub-transmission substations supervisor in preventive maintenance and condition monitoring. His research interests include power market, lightning Protection, $\mathrm{ZnO}$ Surge Arrester Characterization, application of Machine learning, Support Vector Machine (SVM) in electrical engineering. 


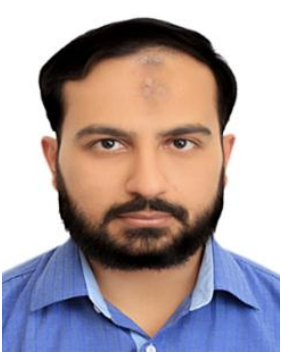

Abdullah Munir received his bachelor's and master's degree in electrical engineering from NED University of Engineering \& Technology, Karachi, Pakistan in 2011 and 2014 respectively. Current he is working on the condition monitoring of gapless metal oxide surge arresters as a PhD scholar in the Institute of High Voltage and High Current (IVAT), Universiti Teknologi Malaysia (UTM), Johor Bahru, Malaysia. He has been serving NED university as a lecturer since 2013. His research interest includes high voltage engineering, condition monitoring of surge arrester, energy conservation and power quality.

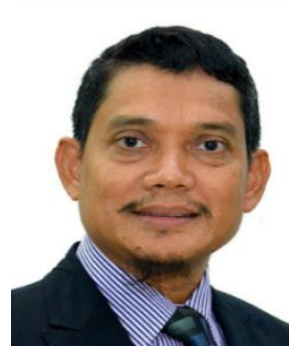

Zulkurnain Abdul Malek received his B.E degree in electrical and computer system from Monash University, Melbourne, Australia in 1989, M.Sc. degree in electrical and electromagnetic engineering from University of Wales Cardiff, Cardiff, United Kingdom in 1995 and Ph.D. degree in high voltage engineering from Cardiff University, United Kingdom in 1999. Currently, he is working as a professor and director of Institute of High voltage and High Current (IVAT), University of Technology Malaysia (UTM) Johor Bahru, Malaysia. He has more than 150 international conference and journal publications along with 40 copyrights and patents. His research interest includes ageing and condition monitoring of surge arresters and power transformers, partial discharge measurement, high voltage and high current transducers, insulating material testing and coordination. 